\title{
Ein Tag Notfalldienst: ein Patient
}

B. Hug

\footnotetext{
* Eigentlich Moses Ben Maimon, geb. 1135 in Cordobà, gestorben 1204 in Fostat bei Kairo. Jüdischer Arzt und Gelehrter.

1 «More Newuchim», 1190 von Maimonides vollendetes religionsphilosophisches Werk.

2 Talmud Shabbat 119a.
}

Korrespondenz:

Dr. med. Balthasar Hug

Kantonsspital

Medizinische Universitätsklinik B

Petersgraben 4

CH-4031 Basel
Das Neonlicht flackerte nervös an der Decke und summte leise vor sich hin. Die Reflexion der gelblichen Plastikvorhänge liess die Gesichter der Schwestern und Ärzte fahl erscheinen. «Ein EKG, bitte!», «Ist das Labor schon hier?», «Der wievielte Eintritt ist das?». Leise Fragen, gerufene Antworten und Gemurmel schwirrten durch den Raum. Zwischenhinein das seufzende Stöhnen eines geplagten Patienten, ein Husten. Gerüche von Desinfizienzien und menschlichen Ausscheidungen hingen in der Luft.

«Kennen Sie Maimonides*?» fragte er mich kurz nach der Begrüssung. Ja, er schrieb den «Führer der Unschlüssigen» [1]. Woher wissen Sie das? War er nicht ein wunderbarer Arzt? Und wie viele Bücher er geschrieben hat! Wissen Sie, wann er gelebt hat? Ja? Seine braunen Augen erschienen riesig hinter den dicken Brillengläsern, schienen einen verschlingen zu wollen. Die Haut war aschfahl, sah ungesund aus, das Kinn stoppelig, rauh und unrasiert. Die faltigen Hände zitterten leicht. Er schien gänzlich unberührt von seinem Spitalaufenthalt, von seiner Schüttelkrankheit, von seiner Umgebung. Nur das Gespräch, sein Inhalt schien ihn zu interessieren; es glich einem Meer, in welches wir wie die Delphine eintauchten.

«Ja, zwölftes Jahrhundert! Wie weit er gereist ist! Und in Ägypten war er Leibarzt des Sultans. Wirklich, ein beachtenswerter Mensch. Wie konnte er seinen Beruf, die Familie und das viele Bücherschreiben unter einen Hut bringen?

Und kennen Sie diese Geschichte? Es war einmal ein Mann, der hiess Joseph. Dieser Mann hielt die Sabbatruhe immer ein. Joseph hatte einen Nachbarn, der viele Güter besass. Da sagten ihm die Leute, dass Joseph durch das Einhalten der Sabbatruhe ihm seinen Reichtum wegnehmen werde. Da verkaufte dieser Mann alle seine Güter und kaufte dafür eine Perle, welche er in seine Kopfbedeckung steckte. Einst fuhr er auf einer Fähre, ein Windstoss kam und wehte ihm seine Kopfbedeckung ins Wasser. Ein Fisch kam und verschluckte die Perle. Als der Fisch an einem Sabbatvorabend an Land gezogen und zum Verkauf gebracht wurde, fragten die Fischer, wer einen solchen kaufen würde? Da sagten die Leute, dass Joseph solche zu kaufen pflegte. Sie brachten den Fisch zu ihm, und er kaufte ihn. Als er den Fisch zubereitete und ihm den Bauch aufschlitzte, fand er die Perle. Diese verkaufte er für dreizehn Mass Golddenare. Da kam ein Greis zu ihm und sprach: Wer dem Sabbat leiht, den bezahlt der Sabbat. Ist diese Geschichte nicht wunderbar?» [2] Seine Stimme hatten einen verklärten Klang, fasziniert von der Parabel.

Das Licht flackerte, hinten tönte das aufgeregte Rufen der Notfallsanitäter, welche einen bewusstlosen Patienten in die Notfallstation hineinfuhren. Die Hektik nahm zu, weissbeschürzte Pflegepersonen schlossen durchsichtige Sauerstoffschläuche an. Kurz darauf hörte man das blasende Geräusch des lebensspendenden Gases. Wie hätte Maimonides in dieser Situation gehandelt?

Wir mussten Abschied nehmen, andere Notwendigkeiten drängten sich auf. «Kommen Sie mich ungeniert besuchen; wir werden unser Gespräch bei mir zu Hause fortsetzen können!» Wie zwei Delphine im Meer. 